\title{
Assessing Noninstitutionalized Asthma and COPD Patients' Priorities and Perceptions of Quality of Health Care: The Development of the QUOTE-CNSLD Instrument
}

\author{
Crétien van Campen, Ph.D., Herman J. Sixma, M.A., \\ Jan J. Kerssens, Ph.D., and Loe Peters, M.A. \\ Netherlands Institute of Primary Health Care (NIVEL) \\ Utrecht, The Netherlands
}

Key words: Chronic nonspecific lung diseases; Asthma; COPD; Questionnaires; Quality of health care

\begin{abstract}
Patient judgments on the quality of health care services have become increasingly important. This research describes the development and empirical testing of an instrument that measures quality of health care services from the perspective of noninstitutionalized patients. The instrument was developed in close collaboration with noninstitutionalized patients with chronic nonspecific lung diseases (asthma and COPD), rheumatic diseases, and disabled and elderly patients. Four instruments were developed with a common generic part and four disease-specific parts. This article focuses on the psychometric properties and the practical use of outcomes for quality assurance policies of the instrument for patients with chronic nonspecific lung diseases.
\end{abstract}

Address correspondence to: Crétien van Campen, NIVEL, P.O. Box 1568, 3500 BN Utrecht, The Netherlands. E-mail: c.vancampen@nivel.nl

Copyright $\odot 1997$ by Marcel Dekker, Inc. 


\section{INTRODUCTION}

In these days of increasing complexity of multidisciplinary health services and rapid growth of health care technologies, improvement and assurance of the quality of health care has become an issue of primary concern. Patient views and judgments on health care services are a vital part of quality assurance in health care (1). Judgments on the quality of care are often formulated by managers and health professionals. However, patient views on the quality of health care differ from the views of health care professionals, managers, insurers, and policy-makers (2-5). Patients' views cannot be inferred from managers' or health professionals' views and should be assessed separately. Reliable and valid assessment of patient views is necessary when it comes to shaping health policies aimed at improvement of the quality of health care for patients suffering from chronic nonspecific lung diseases (CNSLD, including asthma) and chronic obstructive pulmonary diseases (COPD, including chronic bronchitis and emphysema)) (6).

Patient views on the quality of health care have always been assessed by means of patient satisfaction questionnaires. When reviewing a decade of publications on patient satisfaction instruments, we encountered a number of flaws in this field of research $(7,8)$. Instruments that assess patient satisfaction: 1) often produce highly skewed scores $(90 \%$ or more of the respondents are satisfied), 2) produce absolute scores that are not related to individual levels of expectations, needs, wishes, etc., 3) contain items that are formulated on the basis of desk research and not on the basis of patient interviews, 4) evaluate services from the suppliers' instead of the consumers' perspective, and 5) contain generic items only and no diseasespecific items.

The object of this study was to develop an instrument that, in comparison with existing patient satisfaction instruments, would: 1) produce more specific data on health care services, 2) produce data that were related to individuals' needs and expectations, 3) contain items that were formulated in collaboration with patients, 4) measure quality of health care services from the perspective of customers, and 5) produce data on generic items and on disease-specific items of health care services.

This study focused on health care services that are used by noninstitutionalized patients, ranging from the services of home care agencies to specialist care in the hospital. The patient's perspective on health care contains the individual's opinions, needs, experiences, and perceptions of the delivery of the range of health care services. Quality of health care from the consumers' perspective is defined as the degree to which health care services meet the needs of the users of care facilities $(9,10)$. Quality is divided into judgments on the structure, process, and outcome of health care services (9). Consumers' judgments on the quality of health care are assumed to be multidimensional, containing dimensions such as courtesy, information, autonomy, competence, continuity of care, costs, accommodation, and accessibility $(8,11)$. Some dimensions are concerned with the structure, others with the process of quality. Structure quality and process quality of health care services contribute to outcome qualities, i.e., health status, functional status, and quality of life. We assumed the following multidimensional taxonomy: 1) Structure Quality, containing the dimensions Continuity of Care, Costs, Accommodation, and Accessibility, and 2) Process Quality, containing the dimensions Courtesy, Information, Autonomy, and Competence (12).

In the research project "Quality of (Home) Health Care from the Patients' Perspective" four measuring instruments were developed in collaboration with noninstitutionalized patients with CNSLD, rheumatic diseases, disabled patients, and elderly patients (QUOTE-CNSLD, QUOTE-Rheumatic-Patients, QUOTE-Disabled, and QUOTE-Elderly). The four instruments consist of a common general part and four different disease-specific parts. The QUOTE-CNSLD was developed for noninstitutionalized patients with chronic nonspecific lung diseases that need regularly different health care services. Patients of this category use a range of health care services of general practitioners, lung specialists, home helps, and home care agencies.

The research question was: does the QUOTECNSLD provide reliable, valid, and feasible information that can be helpful in shaping qual- 
ity assurance policies of health care services for patients with CNSLD? In this article the main characteristics of QUOTE-CNSLD are discussed, i.e., validity of the taxonomy, scale reliability, and feasibility.

\section{METHODOLOGY}

\section{Patients}

The study was conducted in The Netherlands from August 1993 through December 1995. Participants were selected from the files of CNSLD and asthma patient associations and general practices by means of the following criteria: patients 1) were not institutionalized, 2) used two or more kinds of health care services in the last year (priority to home care users), and 3 ) were suffering from CNSLD (including bronchial asthma, COPD, chronic bronchitis, and emphysema). All selected patients received a written request to participate from their patient association or general practitioner. Patients participated by sending an informed consent form to NIVEL institute. Response rates of the solicited patients were between 50 and $60 \%$. Participants received the questionnaire by mail.

\section{Questionnaires}

The QUOTE-CNSLD instrument was developed for noninstitutionalized patients with CNSLD. This population uses a range of health care services of general practitioners, lung specialists, hospitals, home helps, and home care agencies. The QUOTE-CNSLD instrument consists of 32 indicators of quality of health care, divided over 16 generic and 16 CNSLDspecific indicators. The 32 indicators are applied to 5 health care services of: the general practitioner, the lung specialist, the home help, the home health care agency, and the hospital. As not every indicator is relevant to each discipline, this resulted in 24 indicators for the general practitioner, 24 indicators for the lung specialists, 7 indicators for the home help, 11 indicators for the home health care agency, and 7 indicators for hospital services. The total number of indicators produced by the instrument was 73 .
Participating CNSLD patients were asked to rate the relative importance of the health care service aspect (e.g., "Health professionals should know my problems very well") and to rate the performance on each indicator in their perception (e.g., "My general practitioner knows my problems very well," "My lung specialist knows my problems very well," etc.).

The concept "quality of health care from the consumers' perspective" was operationalized as the product of Importance and perceived Performance, according to the formula: $Q i j=I i j$ $x$ Pij. The quality Judgment $(Q)$ on a health service $(j)$ by an individual patients $(i)$ is equal to the Importance score $(I)$ multiplied by the Performance score $(P)(12)$.

From the beginning patients have been participating in the development of the instrument. A series of focus group discussions with 11 members of the two Dutch CNSLD and asthma patient associations generated a large pool $(n=90)$ of quality of care indicators (13). Content clustering of the pool of indicators resulted in 59 indicators, which were included in the first version of the instrument. In the first empirical test we tested the feasibility of the questionnaire and compared the costs and quality of patient data collection by mail versus telephone versus in-person administration modes (14). The data were analyzed with regard to cost per case, response rates, missing values, and response effects. Verbatim comments from patients were processed in the second version. The quantitative results of the methodological comparison will be published elsewhere (14). It was concluded that the mail mode of administration was the most costeffective and yielded the highest response rates. We adapted the second version, on the basis of item information and by item reduction, to form the final version of the QUOTECNSLD (15).

\section{Statistical Analysis}

Reliability and validity of the scales were evaluated by means of statistical tests of the Importance scores. The Performance scores were excluded from the statistical analyses because they were highly skewed and not stable enough. Since situations change in health 
care services, the performances as perceived by patients will also change, while Importance scores are more stabile over changing situations as they are linked to the attitudes and opinions of patients. The Importance scores proved to be better distributed in our data set.

Validity was evaluated by means of confirmative factor analyses of the presumed taxonomy of Structure Quality versus Process Quality and the General Part versus the CNSLD-specific Part.

Reliability was evaluated by means of test of internal consistency expressed in Cronbach's alpha for the scales of Structure Quality, Process Quality, the General Part, and the CNSLD-Specific Part.

Feasibility was evaluated by means of a comparison of the specific values of the Quality Impact Indices within and between health care services. Quality Impact Indices were calculated for each indicator for each service. The Quality Impact Index is computed by means of the product of the Importance score (range 0-10) and the proportional Performance score (range 0-1). The Performance score represents the proportion of respondents who did not perceive the particular service being performed by the health professional or the health institution.

\section{RESULTS}

As the results of the psychometric analyses of the four QUOTE instruments (QUOTECNSLD, QUOTE-Rheumatic-Patients, QUOTEDisabled, QUOTE-Elderly) will be published elsewhere (15), this article will focus on the main psychometric characteristics of the QUOTE-CNSLD instrument and the information it provides for quality management of the health care services for noninstitutionalized patients with CNSLD.

\section{Subjects}

The sample of respondents consisted of 357 patients with CNSLD; 177 of them had been contacted through patient associations and 180 of them through general practices. The mean age of the respondents was 57 years (SD 18.6) with a range of $15-95$ years; $54 \%$ were female; $24 \%$ were living alone, $76 \%$ with a partner or family; and $49 \%$ were members of a patient association. In the last year the respondents had used two or more health care services: i.e., general practitioner $98 \%$, lung specialist $71 \%$, home help $31 \%$, and home care agency $17 \%$.

\section{Validity}

With respect to the validity of the theoretical framework, confirmative factor analyses showed that the assumed taxonomy was partially confirmed, indicating that an underlying taxonomy of Structure and Process Quality was found in the generic items, not in the disease-specific items. A second division of the items into a generic and CNSLD-specific factor was also confirmed (15).

\section{Reliability}

The structure quality versus the process quality and the generic indicators versus the CNSLD-specific indicators all were shown to be reliable scales to be assessed separately. This affords a reliable use of the entire questionnaire of 32 indicators as well as subscales of Structure Quality (8 indicators), Process Quality (8 indicators) for the general part, Generic Quality (16 indicators), and CNSLDspecific Quality (16 indicators) (Table 1).

Table 1. Internal Consistency of the QUOTE-CNSLD Scale and Subscales

\begin{tabular}{lcc}
\hline (SUB)SCALE & CRONBACH'S ALPHA & INDICATOR NO. \\
\hline QUOTE-CNSLD & .93 & All indicators \\
General QUOTE-CNSLD indicators & .88 & $1-16$ \\
Structure Quality & .84 & $8,10-16$ \\
Process Quality & .80 & $1-9$ \\
CNSLD-specific indicators & .90 & $17-32$ \\
\hline
\end{tabular}




\section{Feasibility}

Table 2 shows the main scores of the empirical evaluation of the instrument. The mean Importance scores (I) of 357 CNSLD patients for each of the 32 indicators of the QUOTECNSLD are represented in the first column of Table 2 . The next columns show the perceived Performance $(\mathrm{P})$ scores and the calculated Quality Impact Indices $(Q)$ for the health care services selected, viz., general practitioners, lung specialists, home helps, home health care agencies, and hospitals.

Table 2 offers at least three types of information relevant for quality improvement. First, the relative importance of quality indicators can be deduced from the first column (I scores). This sample of CNSLD patients rated the indicator no. 19, "When inhalation equipment in hospitals is used by several people, the mouthpiece should be cleaned after use," of the highest importance $(I=9.2)$, followed by indicator no. 18, "When administering anesthetics, one should take into account that I am asthma/ COPD patient" ( $I=8.6)$.

Second, the performance of health care providers and institutions can be deduced from the $P$ columns in Table 2 . For instance the perceived performance of general practitioners (second column) was poor concerning indicator no. 23, "The physician or pharmacist should yearly provide a list of my medicine use." The P score of .88 indicates that according to $88 \%$ of the respondents, the general practitioner did not provide yearly a list of their medicine use.

Third, the relative impact of priorities and perceived performances on quality can be deduced from the $Q$ columns in Table 2. For instance, concerning indicator no. 2, "Health professionals should work efficiently," the impact of this aspect on the quality of the services of home helps ( $Q$ home help $=.54$ ) can be calculated by taking the product of the importance $(I=6.8)$ and the perceived performance by home helps ( $\mathrm{P}$ home helps $=.14$ ).

Table 2 affords information to compare the relative quality impacts within and between professions and institutions. Considering one type of service of, for instance, general practitioners, it is found that indicator no. 25, "Physicians should tell me what to do in emergency situations," has a high-quality impact
$(\mathrm{Q}=4.28)$, as a result of high rating $(\mathrm{I}=6.9)$ and the fact that in the perception of $62 \%$ of the respondents $(P=.62)$ the general practitioner had failed in that respect. A low-quality impact $(Q=.30)$ is found in indicator no. 5 for general practitioners: "Physicians should keep their appointments," as an effect of a rather low rating $(I=5.9)$ and the perceived fact that $5 \%$ of the general practitioners did not keep their appointments $(\mathrm{P}=.05)$.

The quality impact of one indicator over several types of health care services can be considered as follows. The Quality Impact Indices of indicator no. 1, "Health professionals should know my problems very well," differ for the general practitioner (.40), the lung specialist (.34), the home help (1.07), and the home health care agency (1.74). The quality impact indices of home helps and home care agencies are much higher than those of general practitioners and lung specialists.

\section{DISCUSSION}

Our goal was to develop and test, in collaboration with CNSLD patients, a standardized questionnaire that can be used in surveying noninstitutionalized CNSLD patients' judgments on the quality of health care services. Our approach from the consumers' perspective differs from the philosophy behind traditional patient satisfaction questionnaires in a number of respects.

First, in comparison with the general result of $90 \%$ satisfaction often found with traditional patient satisfaction instruments, the results of the first application of this instrument provide a pattern of relatively weak and strong qualities of health care services in the opinions of this sample of noninstitutionalized CNSLD patients. Second, in comparison with most satisfaction instruments, the QUOTE-CNSLD offers indices that are weighted by their importance in the views of the patients. Third, patients played an important role in the development of this instrument, which guarantees that items are included that are important to patients. As a result, not only a number of well-known patient satisfaction items have been generated, but also an equal number of items that are encountered by patients with CNSLD especially. 


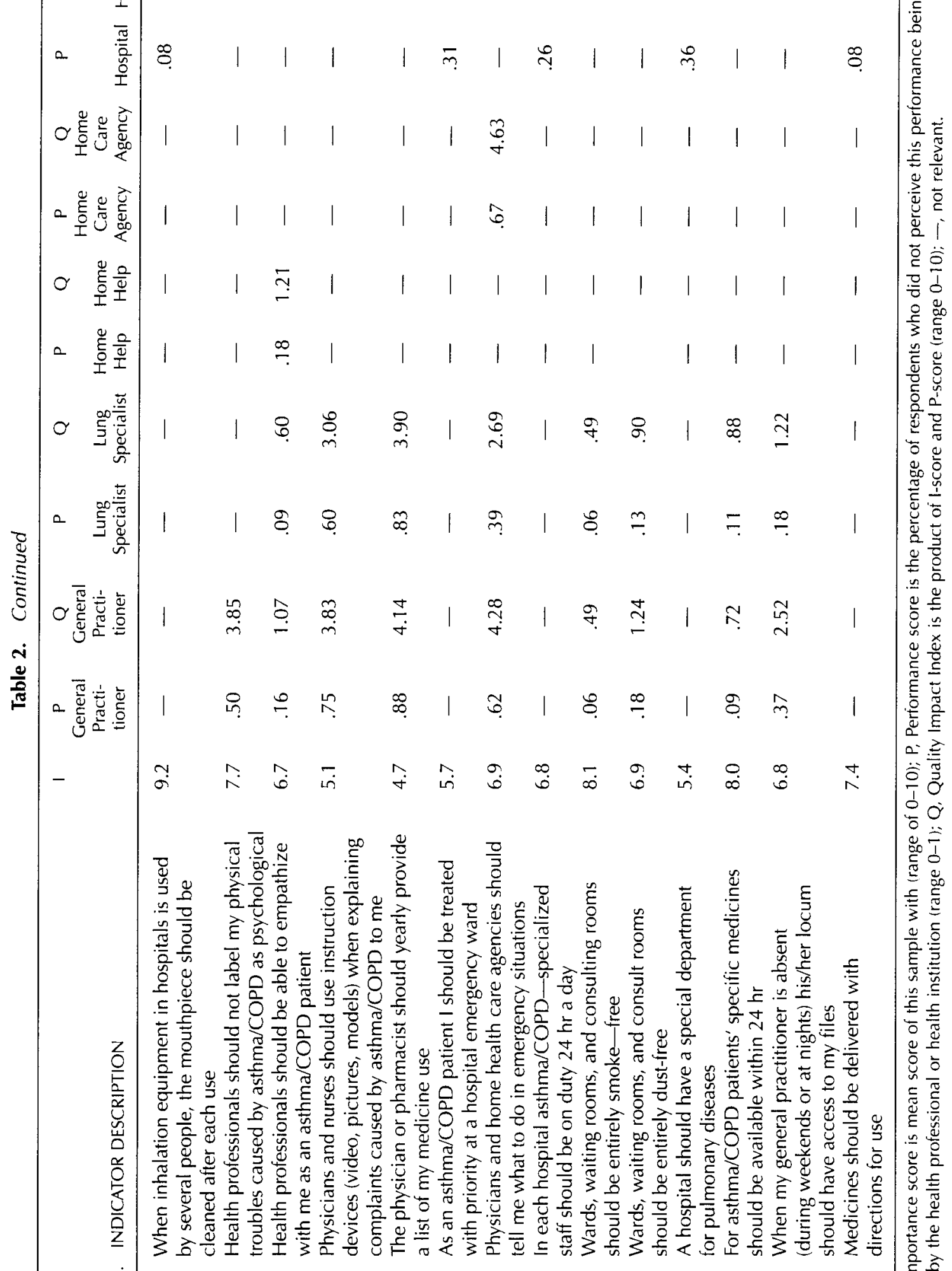


Starting with assessing patient priorities and patient perceptions instead of patient satisfaction has a number of advantages. The QUOTECNSLD provides indices that show which aspects of care will have the greatest impact on the improvement of the quality of care in the view of a group of patients with CNSLD. The results in Table 2 show, for instance, in which branches of health care services quality improvement will have the greatest impact. The maximum quality impact score for this sample of CNSLD patients was 4.28 , indicating that the greatest quality improvement, according to this group of patients, can be gained when general practitioners inform patients better on what to do in emergency situations (no. 25). Another quality improvement impact $(Q=4.14)$ can be gained when general practitioners provide yearly reports on medicine use (indicator no. 23). A quality manager in a hospital, for instance, might be more interested in where quality can be gained in the work of lung specialists. Table 2 shows that, according to these patients, most quality can be gained when lung specialists provide yearly reports on medicine use (indicator no. 23) (Qlung-specialist $=3.90$ ) .

Most patient satisfaction instruments report how patients view the quality of health care. Unfortunately, these results are not often used (or are not feasible) in quality improvement programs. The QUOTE-CNSLD not only offers indices to evaluate the quality of health care services from the perspective of CNSLD patients, but will also be helpful to find where quality improvement might be most gainful.

\section{CONCLUSIONS}

The QUOTE-CNSLD instrument has been shown to be a reliable and valid instrument for assessing the quality of health care sevices from the perspective of noninstitutionalized CNSLD (asthma and COPD) patients. For comparison with other patient groups of noninstitutionalized chronically ill patients, the QUOTECNSLD offers a reliable subscale of general health care indicators. The instrument makes it possible to calculate the relative Quality Impact of indicators, which can be of help in the shaping of quality assurance policies.

\section{ACKNOWLEDGMENT}

The research project "Quality of (Home) Health Care from the Patients' Perspective: Development of an Instrument" was supported by research funds from the Netherlands Organization for Scientific Research (NWO 900-571-054).

\section{REFERENCES}

1. Ovretveit J: Health Service Quality: An Introduction to Quality Methods for Health Services. Blackwell Scientific Publ., London, 1992.

2. Bensing J: Doctor-patient communication and the quality of care. Soc Sci Med 32:1301 (1991).

3. Potts MK, Mazucca SA, Brandt KD: Views of patients and physicians regarding the importance of various aspects of arthritis treatment: Correlations with health status and patient satisfaction. Patient Educ Couns 8:125 (1986).

4. Batalden PB, Nelson EC: Hospital quality: Patient, physician and employee judgements. Int I Qual Assur 3:7 (1991).

5. Waal MAE, Lako CJ, Casparie AF: Voorkeuren voor aspecten van zorg met betrekking tot de kwaliteit: Een onderzoek bij specialisten en bij patiënten met een chronische andoening [Preferences for aspects of care with respect to quality: A study of specialists and chronically ill patients]. Instituut voor Management en Beleid (EUR), Rotterdam, 1993.

6. Dekker FW: Asthma and COPD in general practice: Studies on the quality of care. Leiden: Academic dissertation, Leiden University, 1993.

7. Campen C van, Friele RD, Kerssens JJ: Methods for Assessing Patient Satisfaction with Primary Care: Review and Annotated Bibliography. NIVEL, Utrech, 1992.

8. Campen C van, Sixma H, Kerssens JJ, Peters L: Quality of care and patient satisfaction: A review of measuring instruments. Med Care Res Rev 52:109 (1995).

9. Donabedian A: Explorations in Quality Assessment and Monitoring. Vol. 3. The Methods and Findings of Quality Assessment and Monitoring: An Illustrated Analysis. Health Administration Press, Ann Arbor, MI, 1985.

10. Zastowny TR Stratmann WC, Adamms FH, Fox ML: Patient satisfaction and experiences with health care. Qual Management Health Care 3:50 (1995).

11. Hall JA, Dornan MC: Meta-analysis of satisfaction with medical care: Description of research domain and analysis of overall. Soc Sci Med 27:637 (1988).

12. Sixma HJ, Campen $C$ van, Kerssens JJ, Peters L: Quality of care from the patient's perspective: A theoretical approach. (Submitted).

13. Sixma HJ, Campen C van, Kerssens JJ, Peters L: Focus group methodology and quality of care from the perspective of CNSLD patients. (Submitted.)

14. Campen C van, Sixma HJ, Kerssens JJ, Peters L: Comparisons of the costs and quality of patient data collection by mail versus telephone versus in-person interviews. Eur J Public Health (in press).

15. Sixma HJ, Campen C van, Kerssens JJ, Peters L: Quality of care from the patients' perspective: Four new measuring instruments. (Submitted.) 